\title{
The highest affinity binding site of small protein B on transfer messenger RNA is outside the tRNA domain
}

\author{
LAURENT METZINGER, MARC HALLIER, and BRICE FELDEN \\ Biochimie Pharmaceutique, Inserm U835, Upres JE 2311, Université de Rennes 1, France
}

\begin{abstract}
Eubacterial ribosomes stalled on defective mRNAs are released through a mechanism referred to as trans-translation, depending on the coordinated actions of small protein B (SmpB) and transfer messenger RNA (tmRNA). A series of tmRNA variants with deletions in each structural domain were produced. Their structures were monitored by enzymatic and chemical probes in vitro, in the presence and absence of SmpB. Dissociation constants between these RNAs and SmpB from Aquifex aeolicus were derived by surface plasmon resonance (SPR) combined with filter binding assays. Three independent experimental evidences, including filter binding assays, SPR, and concentration titrations of the RNA-protein reactivity changes toward structural probes, indicate that the binding site that has the highest affinity for the protein is located outside the tRNA domain, upstream of the internal tag. The minimal tmRNA fragment that contains this high affinity site for SmpB, and also contains another site of lower affinity, includes the tag reading frame and three downstream pseudoknots that form a ring structure in solution.
\end{abstract}

Keywords: trans-translation; protein synthesis; ribosome stalling; transfer-messenger RNA; small protein B

\section{INTRODUCTION}

In cells, translation failures can be lethal and have to be dealt with quickly and efficiently by sophisticated qualitycontrol mechanisms. In prokaryotes, mRNAs lacking termination codons or containing rare codons can be stuck on the elongating ribosomes that carry a stalled polypeptide chain. Transfer-messenger RNA (tmRNA), in complex with Small protein B (SmpB), frees the stalled ribosomes for new rounds of protein synthesis and targets both the problematic mRNAs and the incomplete proteins for degradation (for a recent review, see Moore and Sauer 2007). Initially, tmRNA is aminoacylated with alanine and transfers the amino acid to the stalled peptide in the absence of a canonical "codon-anticodon" interaction. Protein synthesis resumes at a short internal open reading frame within the tmRNA sequence, adding a peptide tag to the incomplete polypeptide that is a signal for degradation by specific proteases (Choy et al. 2007). This process is called transtranslation, and can also be triggered during inefficient translation termination (Collier et al. 2002). Structurally,

Reprint requests to: Brice Felden, Biochimie Pharmaceutique, Inserm U835, Upres JE 2311, Université de Rennes 1, France; e-mail: bfelden@ univ-rennes1.fr; fax: 33-02-23234456.

Article published online ahead of print. Article and publication date are at http://www.rnajournal.org/cgi/doi/10.1261/rna.1185808.
tmRNA contains an incomplete tRNA-like domain (TLD) emerging from an interrupted stem (H5) abutting into four pseudoknots (Fig. 1, PK1-PK4). An internal open reading frame is inserted between the first and the second pseudoknots. Crystal structures of a complex between the TLD and SmpB provide a high-resolution view of the RNAprotein interaction, suggesting that $S m p B$ acts as an anticodon mimic at the early steps of trans-translation (Gutmann et al. 2003; Bessho et al. 2007). The detailed structure of the remaining portion of the RNA relies on solution mapping (for a recent study performed on tmRNA from a thermophile, see Metzinger et al. [2005]) combined with cryo-EM reconstructions of the RNA backbone, within the electron density of a preaccommodated "tmRNA-SmpB-EF-Tu-70S" complex (Kaur et al. 2006).

Trans-translation depends on an essential cofactor, SmpB, which binds tmRNA and is required for ribosome recycling and protein tagging in Escherichia coli (Karzai et al. 1999). SmpB mediates tmRNA binding to stalled ribosomes (Hanawa-Suetsugu et al. 2002; Shimizu and Ueda 2002). At an early step during trans-translation, there are two molecules of SmpB per stalled ribosomes, both contacting the TLD (Hallier et al. 2006; Kaur et al. 2006; Gillet et al. 2007). Three-dimensional structures of SmpB from thermophiles $(\sim 135$ amino acids) in solution (Dong et al. 2002; Someya et al. 2003) and bound to the TLD have been determined (Gutmann et al. 2003; Bessho et al. 2007). 
SmpB has an oligonucleotide-binding fold made of a central $\beta$-barrel surrounded by three $\alpha$-helices. The $\sim 20$ residue-long $\mathrm{C}$-terminal tail is essential for function (Jacob et al. 2005; Sundermeier et al. 2005; Hallier et al. 2006), but its structure is disordered outside the ribosome, indicating conformational flexibility. Phylogenetically conserved residues define two surface patches on opposite sides of SmpB (Dong et al. 2002). One coincides with the surface that binds the elbow region of the TLD of tmRNA (Gutmann et al. 2003) and the other most likely contacts the ribosome.

In E. coli, several SmpB molecules can bind to a single tmRNA molecule (Wower et al. 2002). Recently, in Aquifex aeolicus, we showed that tmRNA contains three binding sites for SmpB (Metzinger et al. 2005). Binding of SmpB to the site in the TLD is considered as the high-affinity site that is functionally important (Karzai et al. 1999; Barends et al. 2001; Barends et al. 2002; Hanawa-Suetsugu et al. 2002; Wower et al. 2002; Valle et al. 2003; Nameki et al. 2005). Using structural probes, additional reactivity changes on tmRNA in the presence of the SmpB protein were mapped outside the TLD (Metzinger et al. 2005). These data suggest that $\mathrm{SmpB}$ could bind tmRNA at different locations during the dynamic process of transtranslation, including tmRNA accommodation, message swapping, and tag translation. To define each of these binding sites of SmpB onto tmRNA, we designed and produced a series of 16 tmRNA variants (see Table 1). These synthetic RNAs were assayed for binding to SmpB by filter binding assays and by surface plasmon resonance (SPR). The solution conformations of selected variants

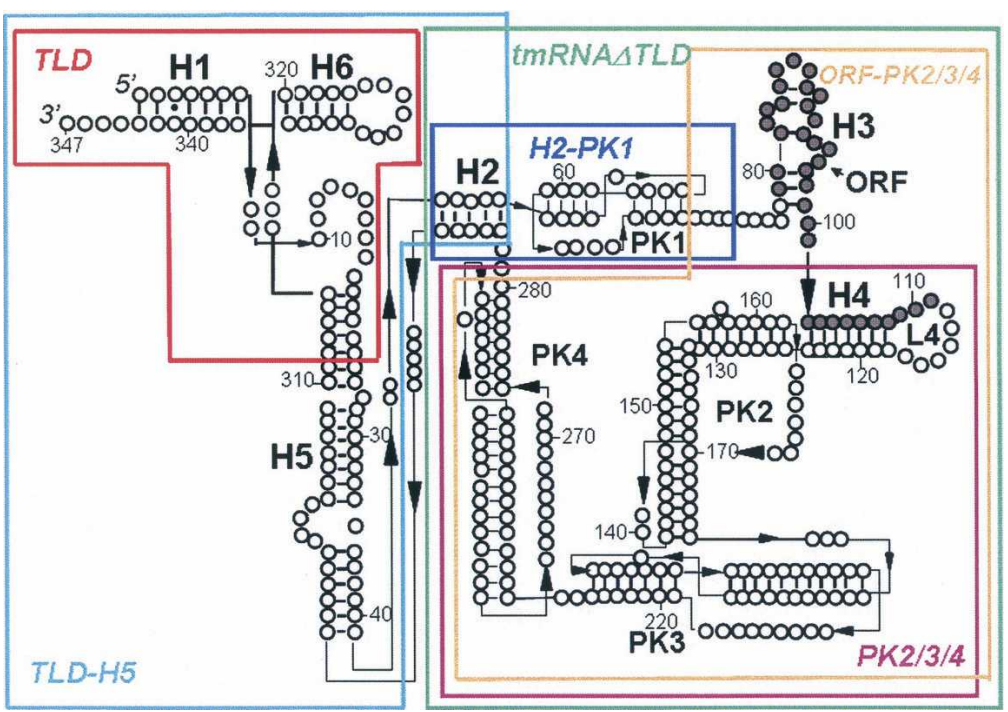

FIGURE 1. Schematic representation of Aquifex aeolicus tmRNA secondary structure and of some of the variants designed and produced. The empty black circles are the nucleotides, the bars are the Watson-Crick pairings, and the stars are the wobble GU pairs. Dark circles mark the open reading frame. The RNA variants are the TLD (63 nt, red), TLD-H5 (114 nt, light blue), H2-PK1 (39 nt, dark blue), PK2/3/4 (179 nt, purple), ORF-PK2/3/4 (211 nt, orange), and tmRNA $\Delta$ TLD (242 nt, green). The complete list of the RNA variants produced is listed on Table 2 . were then confirmed by structural probes to verify their predicted secondary structures, ruling out putative misfolded RNAs. Converging experimental evidences indicate that the site on the tmRNA structure that possesses the highest binding affinity for $\mathrm{SmpB}$, with a $1.6 \pm 0.5 \mathrm{nM} K_{\mathrm{D}}$, is located outside the TLD. This novel high-affinity site for SmpB includes the tag reading frame and requires the presence of three downstream pseudoknots on tmRNA structure that form a closed ring in solution. The binding site cannot be shortened further without loosing the affinity for the protein, most likely for structural reasons.

\section{RESULTS}

\section{Determination of the equilibrium constants of dissociation between SmpB and either tmRNA, TLD, or tmRNA $\Delta$ TLD}

An earlier study (Metzinger et al. 2005) has identified three binding sites of SmpB on tmRNA, including the one on the TLD. To discriminate these binding sites, we used filterbinding assays to measure the affinity of $\mathrm{SmpB}$ from Aquifex aeolicus for synthetic TLD compared to the affinity of the protein for synthetic full-length tmRNA (Fig. 2A,C). At least three independent experiments were performed, and a representative experiment is shown on Figure 2B. When the concentration of $\mathrm{SmpB}$ is at $7.4 \pm 2.3 \mathrm{nM}$, half of the full-length tmRNA binds the protein. However, surprisingly, a concentration of SmpB 6.5-fold or higher ( $47 \pm$ $14 \mathrm{nM}$ ) is required to bind half the TLD. These data suggest that the binding site on tmRNA that has the higher affinity for $\mathrm{SmpB}$ is located outside the TLD. When we determined the affinity of SmpB for a tmRNA variant without the TLD (Fig. 1, tmRNA $\Delta$ TLD, corresponding to domains H2-PK1-ORF-PK2/3/4), the concentration of $\mathrm{SmpB}$ required to bind half this construct $(8.7 \pm 1.5 \mathrm{nM})$ is comparable to the one measured for the fulllength tmRNA (7.4 $\pm 2.3 \mathrm{nM})$ (Fig. 2B). Our results suggest the existence of a SmpB binding site located outside the TLD that has the highest affinity for the protein.

To define with accuracy the binding site(s) located outside of the TLD and to strengthen the filter binding data, SPR analysis was performed to determine the equilibrium dissociation constants $\left(K_{\mathrm{D}}\right)$ between $\mathrm{SmpB}$ and tmRNA. Increasing concentrations of the TLD, tmRNA $\Delta$ TLD or full-length tmRNA were injected over the sensor chip functionalized with purified $\mathrm{SmpB}$ until steady-state binding 


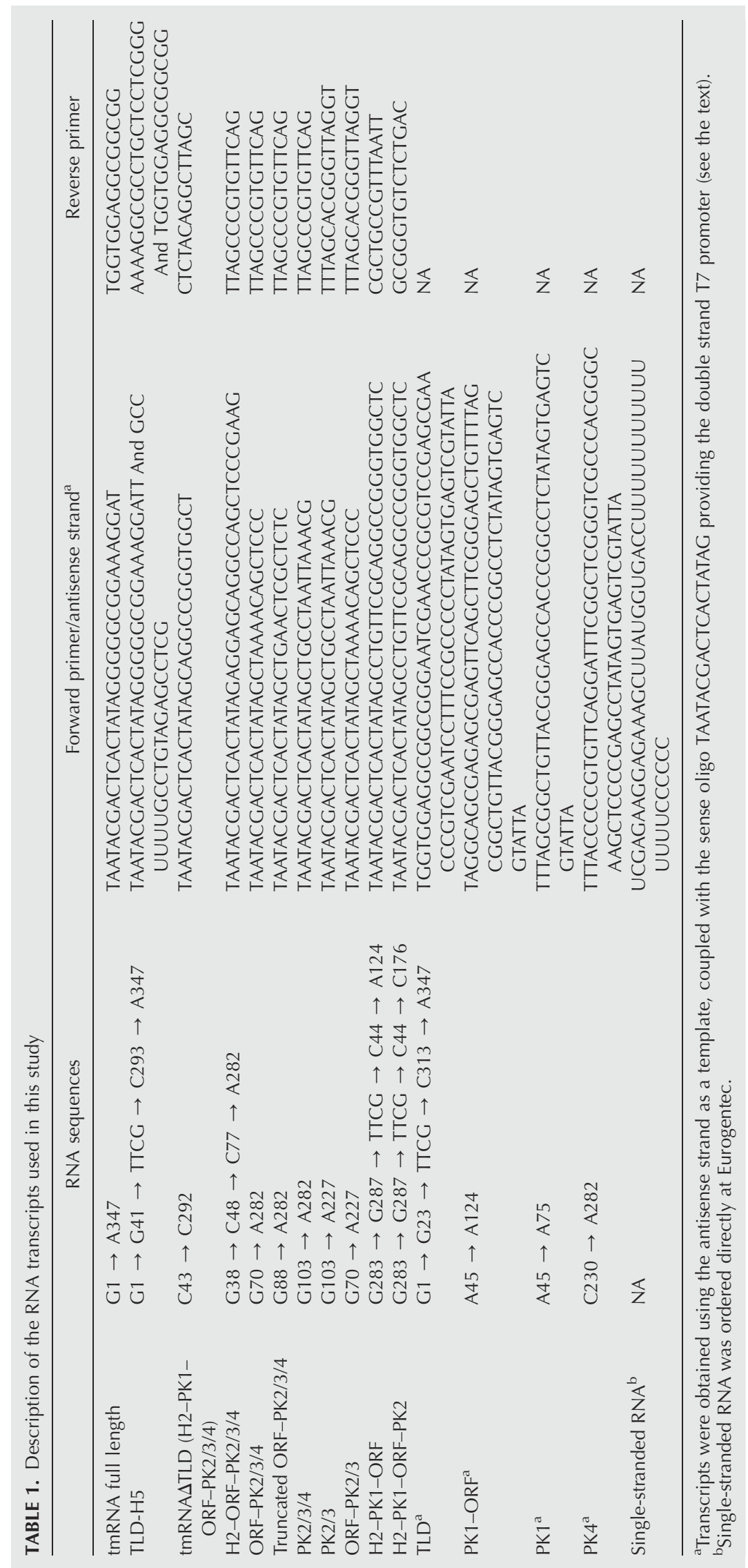


A
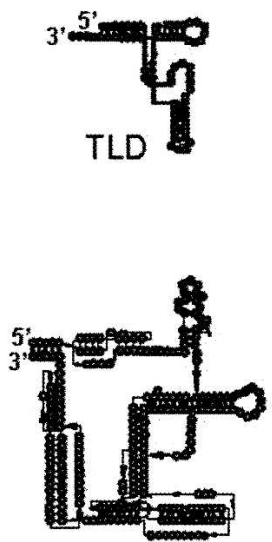

tmRNAATLD
B
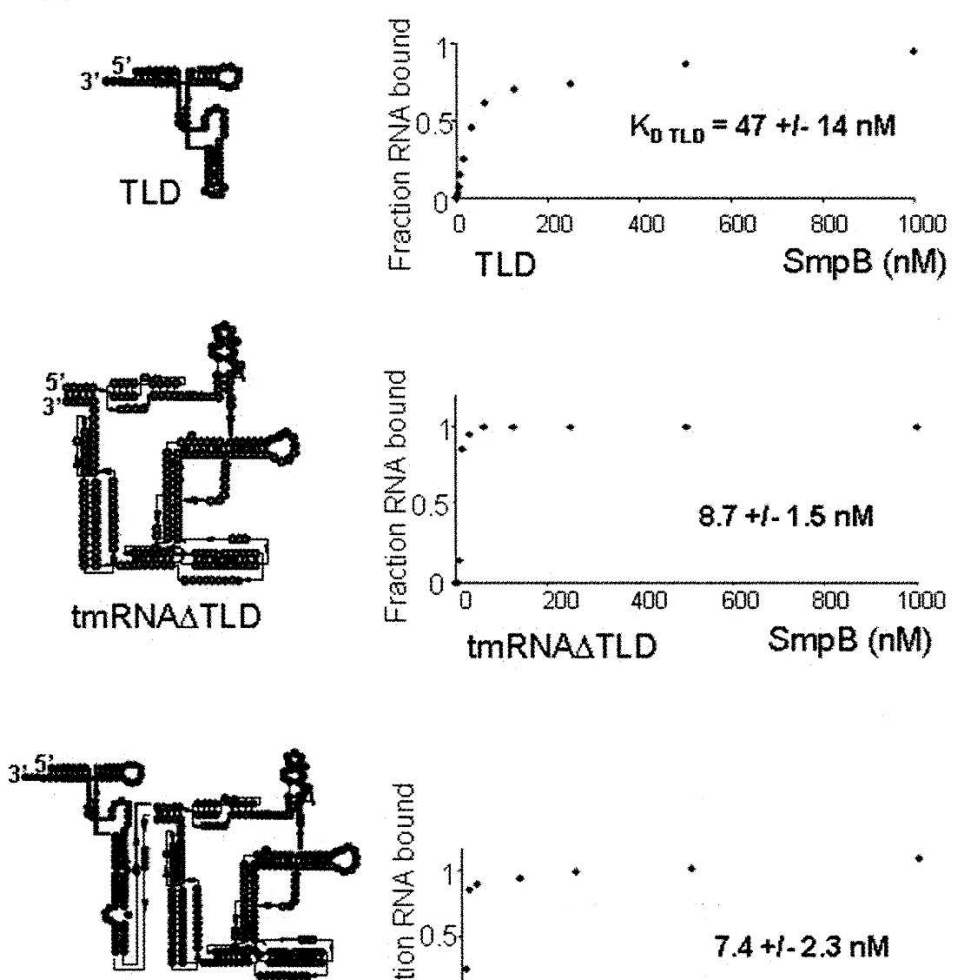

Full-length tmRNA

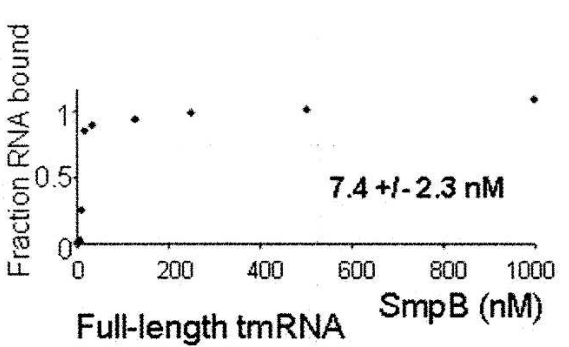

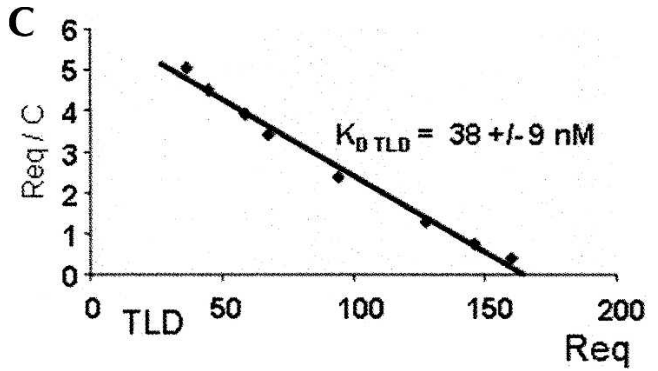
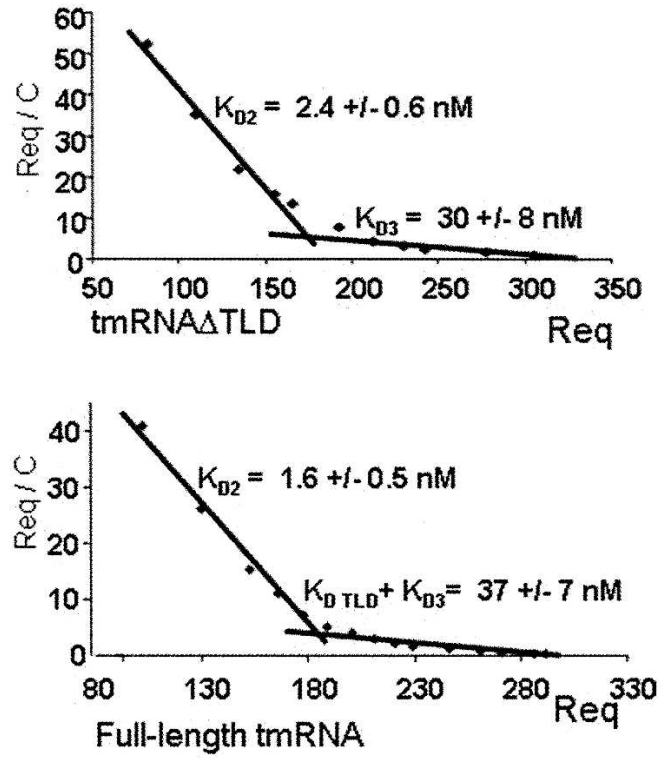

FIGURE 2. Filter binding assays and dissociation constants derived by SPR of purified SmpB with either full-length tmRNA, tmRNA $\Delta$ TLD, or the TLD. (A) Structure of the constructs used. TLD (tRNA-like domain); tmRNA $\Delta$ TLD (H2-PK1-ORF-PK2/3/4); tmRNA full length. (B) The maximum fraction of either tmRNA or the TLD retained on nitrocellulose filters in complex with SmpB was set to 1. The apparent dissociation constants of the tmRNA-SmpB and TLD-SmpB complexes, derived from at least four independent experiments, are indicated. $(C)$ Equilibrium binding response of tmRNA TLD, TLD, and tmRNA $\triangle T L D$ to $S m p B$ versus concentration were obtained by the injection of increasing amounts of the purified analytes to the flow cell immobilized with SmpB. $R_{\mathrm{eq}}$, in RU, was determined when the injection curve showed a plateau, and thus equilibrium was reached. The plot of $R_{\mathrm{eq}} / C$ (where $C$ is the RNA concentration) against $R_{\mathrm{eq}}$ at different RNA concentrations gives a Scatchard plot from which $K_{\mathrm{D}}\left(1 / K_{\mathrm{A}}\right)$ can be calculated. For the binding of either tmRNA or tmRNA $\Delta$ TLD to SmpB, a broken line is observed, favoring two binding sites. The dissociation constants at the equilibrium were obtained from at least three independent experiments, and the standard deviation of each experimental data is indicated.

level was reached. At least three independent experiments were performed, and a Scatchard representation of the data is shown in Figure $2 \mathrm{C}$. The dissociation constant $\left(K_{\mathrm{D}} \mathrm{TLD}\right)$, derived from SPR between SmpB and the TLD, is $38 \pm 9$ $\mathrm{nM}$, in agreement with data extracted from the filter binding assays (Fig. 2B). Interestingly, the Scatchard representation of the dissociation constants derived from SPR between SmpB and tmRNA $\triangle$ TLD reveals two binding sites: one of high $\left(2.4 \pm 0.6 \mathrm{nM} K_{\mathrm{D} 2}\right)$ and one of lower $\left(30 \pm 8 \mathrm{nM}, K_{\mathrm{D} 3}\right)$ affinities. That second experimental approach confirms that the higher affinity binding site for SmpB is outside the TLD $\left(K_{\mathrm{D} 2}\right)$, and reveals that a second, lower affinity site exists on this variant $\left(K_{\mathrm{D} 3}\right)$. Since the TLD has a $\sim 40 \mathrm{nM} K_{\mathrm{D}}$, and since the low-affinity site for $\mathrm{SmpB}$ on the tmRNA $\Delta \mathrm{TLD}$ has also a $\sim 40 \mathrm{nM} K_{\mathrm{D}}$, these two sites cannot be visualized separately onto full-length
tmRNA. Indeed, for full-length tmRNA, the Scatchard representation gives two $K_{\mathrm{Ds}}$ : one has an affinity of $1.6 \pm$ $0.5 \mathrm{nM}$ for SmpB, corresponding to the "high-affinity" site found on tmRNA $\triangle \mathrm{TLD}\left(K_{\mathrm{D} 2}\right)$, as well as a site of lower affinity (37 $\pm 7 \mathrm{nM}$ ) (Fig. 2C), corresponding to an average of $K_{\mathrm{D}}$ TLD and $K_{\mathrm{D} 3}$. In this work, we will refer to these binding sites as low- $\left(K_{\mathrm{D}}\right.$ TLD and $\left.K_{\mathrm{D} 3}\right)$ and high- $\left(K_{\mathrm{D} 2}\right)$ affinity binding sites.

The SPR data reveal the high-affinity binding site on fulllength tmRNA that is consistent with the very sharp shift observed at low SmpB concentration on the filter binding assays (Fig. 2B). The $7.4 \pm 2.3 \mathrm{nM} K_{\mathrm{D}}$ of full-length tmRNA (Fig. 2B) corresponds to an average value of the three independent binding sites identified by SPR. These two methods, one in solution and the other by attaching SmpB onto a chip, are comparable, since both lead to a 
similar affinity for the TLD (Fig. 2B,C) that contains a single binding site in solution, outside the ribosome, as previously shown by X-ray crystallography (Gutmann et al. 2003).

To address the specificity of the interaction, SPR binding assays between $S m p B$ and either TLD, tmRNA $\triangle T L D$, or full-length tmRNA were also performed in the presence of a 10-fold excess of yeast total RNAs, selected as nonspecific RNA competitors, to mimic the overall amount of total RNAs in the cell. As reported, SmpB from E. coli binds tRNAs with a fivefold lower affinity constant that for tmRNA (Karzai et al. 1999). SmpB from A. aeolicus binds to tRNA ${ }^{\text {phe }}$ with a $105 \mathrm{nM} K_{\mathrm{D}}$ (Table 2). Despite such a binding constant, there is no physiological relevance of an interaction between canonical tRNAs and SmpB during trans-translation. In the presence of a large excess of competitor RNAs containing tRNAs, the affinity of SmpB for its tmRNA binding sites decreases since the $K_{\mathrm{Ds}}$ increase. Indeed, for the TLD, the presence of the RNA competitors increases the $K_{\mathrm{D}}$ from 38 to $1300 \mathrm{nM}$. For both the tmRNA $\Delta$ TLD and full-length tmRNA, the $K_{\mathrm{D}}$ of the high-affinity binding site increase from $2.4 \mathrm{nM}$ to $68 \mathrm{nM}$ and $1.6 \mathrm{nM}$ to $83 \mathrm{nM}$, respectively. Due to the large excess of competitor RNAs, the low-affinity site for SmpB cannot be determined. In the presence of a large excess of competitor RNAs, our data reveal that the high-affinity binding site for $\mathrm{SmpB}\left(K_{\mathrm{D} 2}\right.$ of 68 and $\left.83 \mathrm{nM}\right)$ is outside the TLD $\left(K_{\mathrm{D}}\right.$ TLD of $\left.1300 \mathrm{nM}\right)$.

TABLE 2. Determination of the dissociation constants at the equilibrium, in $\mathrm{nM}$, between SmpB and various synthetic tmRNA variants from Aquifex aeolicus by SPR

\begin{tabular}{|c|c|c|c|c|}
\hline RNAs & $K_{\mathrm{D}} \mathrm{TLD}$ & $K_{\mathrm{D} 2}$ & $K_{\mathrm{D} 3}$ & $K_{\mathrm{D}}^{\mathrm{b}}$ \\
\hline Full-length tmRNA & $37 \pm 7$ & $1.6 \pm 0.5$ & $37 \pm 7$ & \\
\hline TLD & $38 \pm 9$ & & & \\
\hline TLD-H5 & $36 \pm 11$ & & & \\
\hline tmRNA $\triangle$ TLD & & $2.4 \pm 0.6$ & $30 \pm 8$ & \\
\hline$(\mathrm{H} 2-\mathrm{PK} 1-\mathrm{ORF}-\mathrm{PK} 2 / 3 / 4)$ & & & & \\
\hline H2-ORF-PK2/3/4 & & $2.0 \pm 0.1$ & $30 \pm 15$ & \\
\hline PK1 & & & & 500 \\
\hline H2-PK1 & & & & 120 \\
\hline PK1-ORF & & & & 180 \\
\hline H2-PK1-ORF & & & & 160 \\
\hline H2-PK1-ORF-PK2 & & & & 80 \\
\hline ORF-PK2 & & & & 200 \\
\hline ORF-PK2/3 & & $32 \pm 6^{c}$ & & \\
\hline ORF-PK2/3/4 & & $4.1 \pm 0.1$ & $18 \pm 4$ & \\
\hline Truncated ORF-PK2/3/4 & & & & 180 \\
\hline PK4 & & & & 360 \\
\hline PK2/3 & & & & 240 \\
\hline $\mathrm{PK} 2 / 3 / 4$ & & & & 295 \\
\hline Single-stranded $R N A^{a}$ & & & & 235 \\
\hline tRNA ${ }^{\text {Phe a }}$ & & & & 105 \\
\hline
\end{tabular}

${ }^{\mathrm{a}} \mathrm{RNAs}$ used as negative controls.

${ }^{\mathrm{b}} K_{\mathrm{Ds}}$ equal or higher than $80 \mathrm{nM}$.

"Proposed to be a "weakest equivalent" of $K_{\mathrm{D} 2}$.

The error bars have been derived from three independent experiments.
Native tmRNA possesses two modified nucleosides within its T loop in the TLD (Felden et al. 1998). As for canonical tRNAs, they participate in the interaction between the T loop and the D-analog, based on NMR data (Gaudin et al. 2003). Therefore, a reasonable assumption is that a native TLD, with its modified nucleosides, has higher affinity for the SmpB protein. We tested a TLD RNA purified in vivo. This RNA (sequence described in Gaudin et al. 2003) binds SmpB with a $K_{\mathrm{D}}$ of $13 \pm 4 \mathrm{nM}$, which is of higher affinity compared with the synthetic RNA with an identical nucleotide sequence, that has a binding constant of $38 \pm 1 \mathrm{nM}$ (data not shown). The affinity of the native TLD is, however, fivefold lower than that of SmpB for tmRNA $\Delta$ TLD ( $2.4 \pm 0.6 \mathrm{nM})$ (Table 2). Taken together, these data demonstrate that, on full-length tmRNA, the binding site that has the higher affinity for $\mathrm{SmpB}$ is not located on the TLD, either with or without its modified nucleosides, but on the remaining part of the RNA structure (tmRNA $\Delta \mathrm{TLD})$.

\section{Determining the binding constants between 16 tmRNA variants and SmpB by SPR}

In an attempt to delineate the binding sites of SmpB outside the TLD with accuracy, synthetic RNA constructs derived from the tmRNA wild-type sequence were designed and produced (Fig. 1). All these RNAs were purified, and their dissociation constants with $\mathrm{SmpB}$, at the equilibrium, measured by SPR (Table 2). Structural mapping in solution performed on selected tmRNA variants rule out putative conformational heterogeneity (Gutmann et al. [2003] for the TLD, Metzinger et al. [2005] for tmRNA, and this work for the tmRNA $\triangle T L D$ [see below]). Since the SmpB protein binds tRNAs and double-stranded RNAs weakly and without specificity (Wower et al. 2002), purified tRNA ${ }^{\text {Phe }}$ from yeast and single-stranded RNAs with random sequences were included as internal controls. Full-length tmRNA displays three independent binding sites (Metzinger et al. 2005): one on the TLD and two others outside the TLD (Fig. 2). Out of these three sites in full-length tmRNA, two sites have similar $K_{\mathrm{D}}$ values: $K_{\mathrm{D}}$ TLD and $K_{\mathrm{D} 3}$ (Fig. 2; Table 2).

Adding domain $\mathrm{H} 5$ to the TLD (Fig. 1) has no positive or negative effects on binding SmpB, indicating that $\mathrm{H} 5$ is not part of a recognition motif for the protein. PK1 is required for efficient trans-translation (Nameki et al. 1999a; Nameki et al. 1999b; Nameki et al. 
2000). To assay the existence of a putative interaction between PK1 and SmpB in the context of tmRNA structure, a construct missing PK1 (Table 2, H2-ORF-PK2/3/4) was analyzed by SPR with SmpB. This RNA still possesses two binding sites for the protein and both $K_{\mathrm{Ds}}$ (Table $2, K_{\mathrm{D} 2}=$ $\left.2.0 \mathrm{nM} \pm 0.1, K_{\mathrm{D} 3}=30 \mathrm{nM} \pm 15\right)$ are identical to those of tmRNA $\Delta$ TLD. Furthermore, PK1 by itself has no affinity for the protein (a $500 \mathrm{nM} K_{\mathrm{D}}$ ). Taken together, these in vitro results demonstrate that there are no specific interactions between PK1 and SmpB. Also, within the tmRNA structure, PK1 has no contributions to the binding affinity with the protein. Adding upstream (H2) or downstream (the ORF) structural elements to PK1 only very slightly improves the binding affinity with the protein (Table 2). By removing $\mathrm{H} 2$ and $\mathrm{PK} 1$ from tmRNA $\Delta \mathrm{TLD}$, the construct starts at G70 and ends at A282. This RNA (ORF-PK2/3/4) maintains the two binding sites for $\mathrm{SmpB}$ without significantly affecting their dissociation constants (Table 2, $K_{\mathrm{D} 2}=$ $\left.4.1 \mathrm{nM} \pm 0.1, K_{\mathrm{D} 3}=18 \mathrm{nM} \pm 4\right)$. We tested a construct with a 10 -nucleotide (nt) further $5^{\prime}$ truncation of ORFPK2/3/4 (Table 2, truncated ORF-PK2/3/4, $K_{\mathrm{D}}$ of $180 \mathrm{nM}$ ). This construct leads to the loss of the two binding sites for SmpB, showing that nucleotides between nucleotides 70 and 77 are essential for maintaining the high-affinity binding site and also the low-affinity binding site outside the TLD. This nucleotide sequence is not sufficient to form a binding site for $\mathrm{SmpB}$, since various tmRNA constructs possessing the nucleotide sequence 70-77, as for constructs PK1-ORF, H2-PK1-ORF and H2-PK1ORF-PK2, are unable to bind to $\mathrm{SmpB}$ with a relevant affinity (Table 2). Truncation variants from the $3^{\prime}$ part of tmRNA $\Delta \mathrm{TLD}$, removing PK4 (the ORF-PK2/3 construct), induce the loss of one binding site. We cannot rule out, however, that in this construct the affinity of $K_{\mathrm{D} 2}$ decreases and becomes equivalent to $K_{\mathrm{D} 3}$, maintaining two sites with identical affinities. SmpB binds the ORF-PK2/3 construct with an affinity comparable to that of $K_{\mathrm{D} 3}(32 \mathrm{nM} \pm$ 6), suggesting that PK4 is part of the high-affinity binding site $\left(K_{\mathrm{D} 2}\right)$. Alternatively, the deletion of PK4 could lead to the loss of the low affinity binding site and to transform the "high-affinity" site to a "low-affinity" one. Structural data of tmRNA derived by cryo-EM reconstructions strengthen this hypothesis, since there is close proximity between PK4 and the "PK1-ORF" junction (see Fig. 5 for details). Pseudoknot PK4 by itself has no affinity for the protein $\left(K_{\mathrm{D}}\right.$ of $\left.360 \mathrm{nM}\right)$. However, our results suggest that PK4 has an important contribution to the conformation of the upstream portion of the RNA (PK3, PK2, and the ORF). Further reduction of the size of the RNA (maintaining only the ORF and PK2) removes the protein binding sites. A construct comprising the three pseudoknots PK2, PK3, and PK4 cannot bind SmpB with high affinity, indicating the essential contribution of nucleotides upstream of the tag for binding, as suggested by the probing data. So, each of the four pseudoknots, either alone or in combination with one another, do not provide accurate recognition signals for the protein, with dissociation constants comparable to a singlestranded RNA (Table 2, $235 \mathrm{nM}$ ). Altogether, these data demonstrate that the binding sites for SmpB outside the TLD are located within the structural ring formed by the PK1-ORF junction, the ORF, and the three downstream pseudoknots, and that the conformation of this subdomain is essential for binding the protein. Also, it shows that PK1, $\mathrm{H} 2, \mathrm{H} 5$, and the TLD are dispensable for the high-affinity binding site (Fig. 5).

\section{TmRNA $\Delta$ TLD has a solution conformation similar to that of full-length tmRNA}

In order to study the interactions between tmRNA $\Delta$ TLD and $\mathrm{SmpB}$ further, structural studies in solution were undertaken. We first studied the structure in solution of tmRNA $\Delta$ TLD from $A$. aeolicus and compared it to the one we published for full-length tmRNA (Metzinger et al. 2005). The purpose of this assay was to determine whether or not this shortened RNA, lacking both the TLD and H5, folds as the intact tmRNA sequence. A tmRNA $\Delta$ TLD transcript was end-labeled at both ends, and its solution conformation was probed by ribonuclease $\mathrm{V}_{1}$ that cleaves double-stranded (ds) RNAs or stacked nucleotides, by nuclease $S_{1}$ or lead, both that cleave single-stranded (ss) RNAs. The reactivity toward these probes was monitored for the 242-ntlong synthetic RNA, except for PK3, which is difficult to map from the two ends of the RNA. Ten independent experiments were performed, and Figure 3 is a representative. These data are summarized on a secondary structure model that they, together with the phylogenetic analysis, support (Fig. 3). $\mathrm{V}_{1}$ cuts suggest that stems $\mathrm{H} 3$ and $\mathrm{H} 4$, as well as the two stems of PK1 and PK4, form in solution, as in full-length tmRNA. Loop 4 (Fig. 3, L4, encompassing the termination codon of the internal tag reading frame) is heavily cleaved by lead and by nuclease S1, as observed for the full-length tmRNA (Metzinger et al. 2005). Nucleotides between PK1 and H3 are cleaved by nuclease $S_{1}$ and by lead, suggesting a high solvent exposure within the RNA structure, as in full-length tmRNA (Metzinger et al. 2005). The internal coding sequence, the ORF from nucleotides 79 (5'-resume) to 111 ( $3^{\prime}$-stop), as drawn in Figure 3, is supported by the cleavage pattern. Lead and $\mathrm{S} 1$ cleavages at the two predicted single strands within PK2, with no cleavages within the predicted stems, support its folding in solution. Both stems of PK4 are cut by RNase V1, and several S1 cuts support the single connecting strands, suggesting that PK4 also forms within tmRNA $\Delta$ TLD. Despite V1 cuts within the helices of PK1 and $\mathrm{H} 3$, lead cleaves from G55 to C65, G67 to C69, C71 to C77, and from G79 to U101. This suggests that $\mathrm{PK} 1$ and $\mathrm{H} 3$ are breathing in solution, more than in full-length tmRNA (Metzinger et al. 2005), due to the absence of $\mathrm{H} 5$ and the TLD that stabilize the two ends of the molecule. Overall, with the exception of PK3 for which 


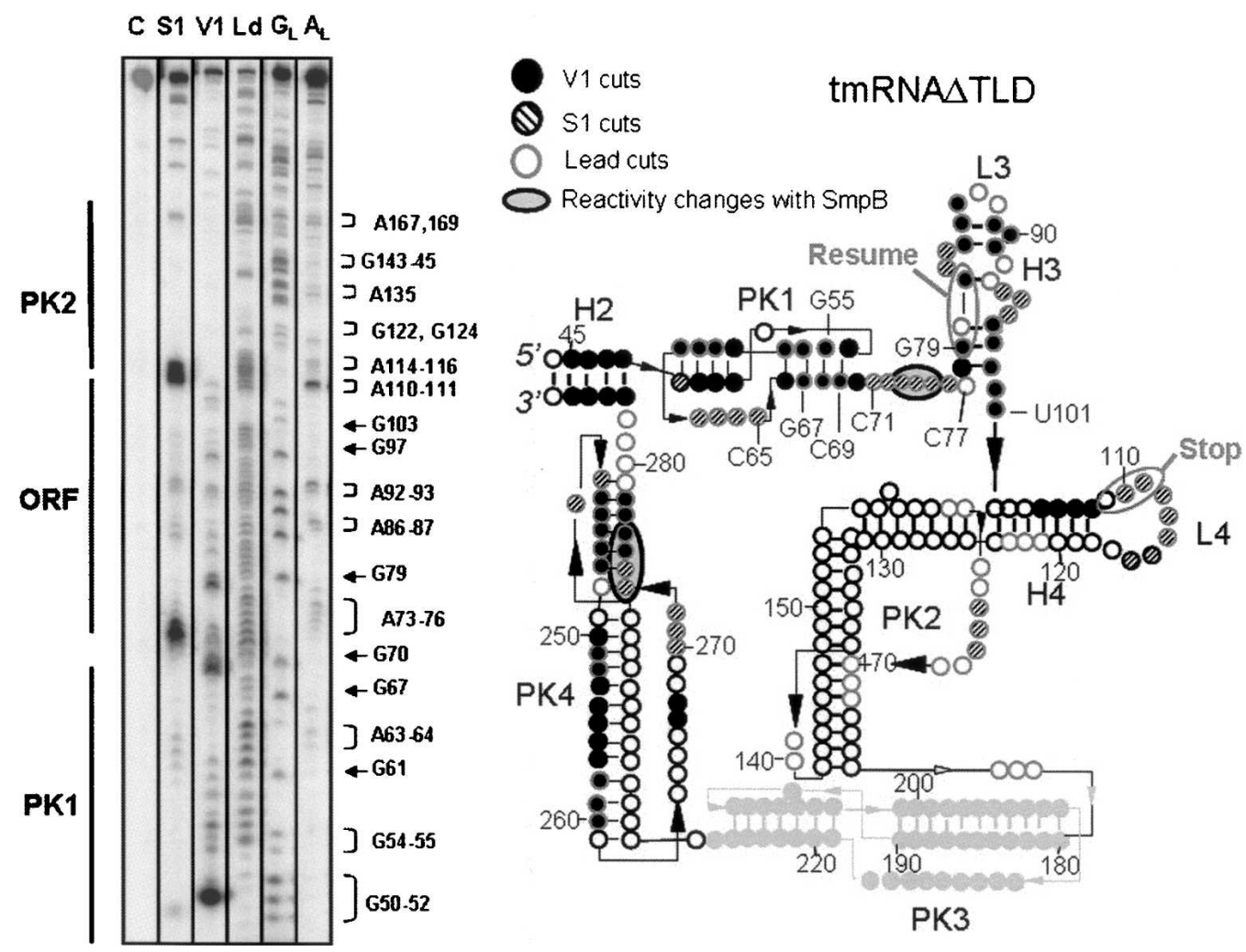

FIGURE 3. Probing the conformation of tmRNA $\triangle$ TLD in solution. (Left) Autoradiogram of cleavage products of $5^{\prime}$-labeled tmRNA $\Delta$ TLD by lead acetate (Ld), nuclease $S_{1}$, and RNase $\mathrm{V}_{1}$. Lane $C$, incubation control; lanes $G_{L}$ and $A_{L}$, RNases $\mathrm{T}_{1}$ and $\mathrm{U}_{2}$ hydrolysis ladders, respectively. The RNA sequence is indexed on the right and the structural domains on the left of the panel. (Right) Secondary structure of tmRNA $\Delta$ TLD from A. aeolicus inferred by structural mapping in solution. The numbering corresponds to that of full-length tmRNA, for direct comparison. The meaning of the symbols is detailed in the inset. Structural domains, such as the pseudoknots (PK), the helices (H), and the loops (L), are indicated. The internal open reading frame (ORF) is indicated. Structural information is missing for PK3 (pale gray). The black bars are the Watson-Crick (GC or AU) pairs. The resume and stop codons are circled.

structural information could not be extracted from our data, the solution conformation of tmRNA $\Delta$ TLD is nearly identical to that of full-length tmRNA.

\section{Analyzing the interactions between $\mathrm{SmpB}$ and tmRNA variants by structural probes}

The interactions between saturating concentrations (400 $\mathrm{nM}$ ) of SmpB and either TLD or tmRNA $\triangle T L D$ were mapped by V1, S1, and lead. Reactivity changes of the nucleotides from the RNAs when the protein is added either come from direct contacts between the two interacting macromolecules or from indirect conformation changes. These data were compared to those reported for full-length tmRNA (Metzinger et al. 2005). For the TLD, the structural data are in agreement with those reported earlier (Gutmann et al. 2003), as well as with those collected in fulllength tmRNA (Metzinger et al. 2005). The modifications of reactivity of nucleotides from tmRNA $\Delta$ TLD induced by SmpB are summarized on Figure 4. SmpB, upon binding tmRNA $\Delta$ TLD, induces protections against $S 1$ cleavages of a single-stranded nucleotide stretch between PK1 and the resume codon (nucleotides A73-A75), upstream of the tag reading frame, as previously described for full-length tmRNA (Metzinger et al. 2005) (see Fig. 3). In a previous work (Metzinger et al. 2005), we reported that SmpB protects PK1 from being modified by structural probes at a $750 \mathrm{nM}$ protein concentration (higher than the $\sim 500 \mathrm{nM} K_{\mathrm{D}}$ of SmpB for PK1). At lower concentration used here (400 nM, lower than the $K_{\mathrm{D}}$ of SmpB for PK1), the reactivity changes are not detected. In PK4, SmpB prevents nucleotides A274G277 from being cleaved by nuclease S1 (see Fig. 3). Therefore, the folding of PK4 is stabilized in the presence of SmpB since A274-G277 is paired within the second stem of the pseudoknot and should not be cleaved by S1 when PK4 is folded. In full-length tmRNA, we reported that nucleotides 270-272 are protected by SmpB against V1 cuts (Metzinger et al. 2005). In tmRNA $\Delta$ TLD, nucleotides 274277 are protected against S1 cuts. Therefore, in the two RNAs, SmpB induces structural changes at the same region of the RNA. In full-length tmRNA, however, this domain is double stranded, whereas in tmRNA $\Delta$ TLD, it is partly unfolded, most likely because the absence of the TLD destabilizes this area of the molecule. Overall, our experimental 


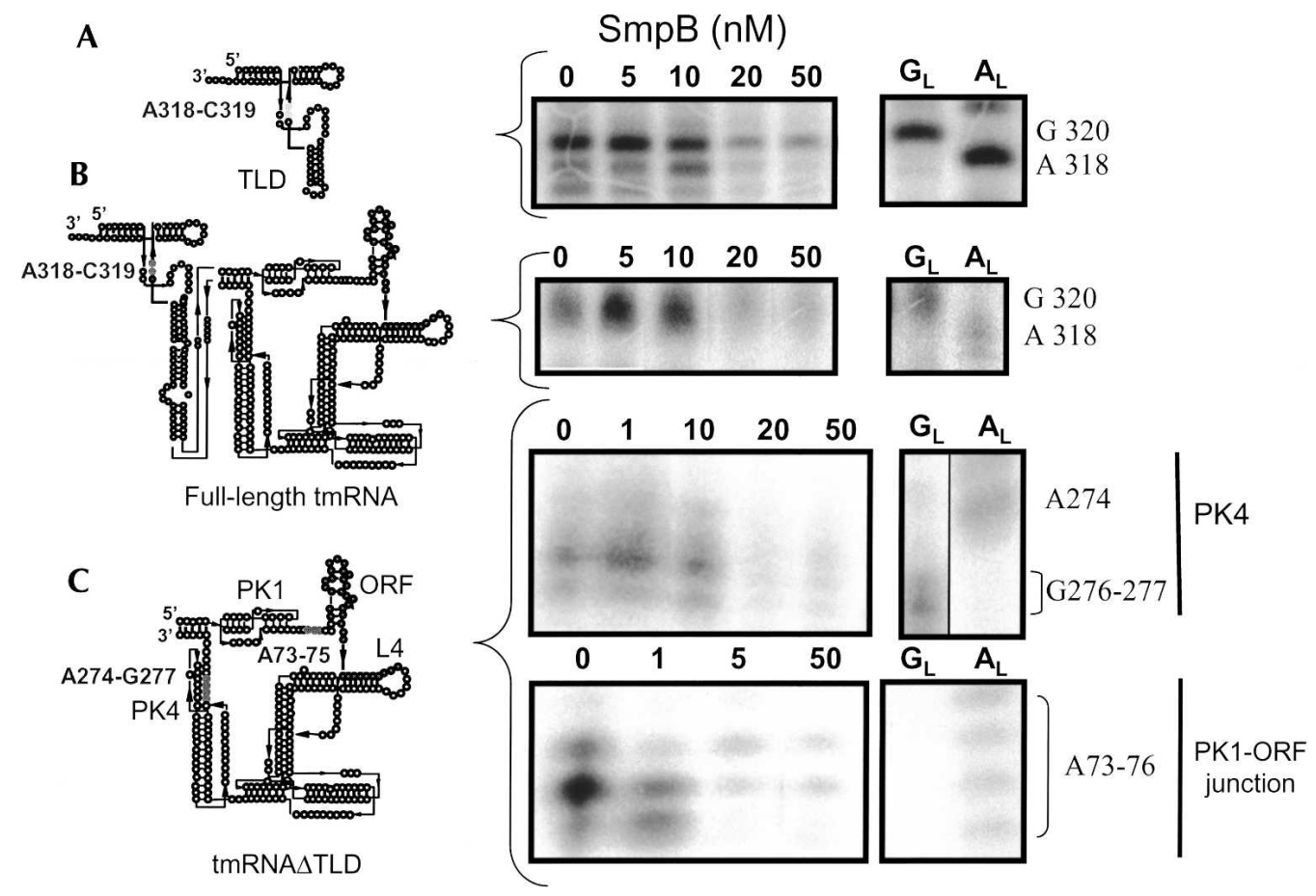

FIGURE 4. The high-affinity binding site between $S m p B$ and tmRNA is located outside the TLD, as revealed by structural probing. Concentration titration of SmpB with either the TLD $(A)$, tmRNA full length $(B)$, or tmRNA $\triangle$ TLD $(C)$ revealed by enzymatic structural probes (nuclease S1). Lanes 0 , incubation of the RNAs in the absence of SmpB; lanes $G_{L}$ and $A_{L}, R_{N a s e s} \mathrm{~T}_{1}$ and $\mathrm{U}_{2}$ hydrolysis ladders, respectively. Accessible nucleotides from either the connecting loop of TLD (gray dots on the TLD structure) or from PK4 in tmRNA $\Delta$ TLD are protected from S1 cleavages at a $20 \mathrm{nM}$ concentration of SmpB or higher. Nucleotides upstream and at the $3^{\prime}$ end of the internal tag reading frame (gray dots on the tmRNA $\triangle$ TLD structure) are protected from S1 cleavages at a $1 \mathrm{nM} \mathrm{SmpB}$ concentration and higher.

data show that the modifications of the probing pattern of tmRNA outside the TLD, when SmpB is present at saturating concentrations, are similar between full-length tmRNA and tmRNA $\triangle T L D$, with only minor differences.

Increasing incrementally the concentration of $\mathrm{SmpB}$ and monitoring the reactivity changes of nucleotides from the RNA toward structural probes should help delineating the protein binding sites. At first, we monitored the footprints of the protein onto the TLD, using incremental concentrations of $\mathrm{SmpB}$, from 1 to $50 \mathrm{nM}$. As expected from the structure of the TLD-SmpB complexes (Gutmann et al. 2003), the protein protects nucleotides from the D- and connector loops as well as three nucleotides from the Tstem (Fig. 1, H6) from being cleaved by ss-specific probes (not shown). Interestingly, the lower concentration of SmpB that protects nucleotides A318 and C319 (connector loop) from the TLD from being cleaved by nuclease $S 1$ is 20 $\mathrm{nM}$ (Fig. 4A). A similar concentration of $\mathrm{SmpB}$ was required to protect the D-loop as well as three nucleotides at the base of the T-stem from being cleaved (not shown). Additionally, we have compared by structural probes the conformation of the TLD in the TLD RNA construct and in the context of the full-length tmRNA. The reactivity toward structural probes indicates that the conformation of the TLD is essentially similar in both RNAs (data not shown).
We have also shown that, between the two RNA constructs, an identical concentration of $\mathrm{SmpB}$ is required to protect nucleotides A318 and C319 from S1 cuts within the two RNA frameworks (Fig. 4B).

Our SPR data collected on the truncated ORF-PK2/3/4 indicate that nucleotides $70-77$ are essential for maintaining two SmpB binding sites onto tmRNA outside the TLD (Table 2). If this nucleotide sequence belongs to the highaffinity binding site, reactivity changes of these nucleotides toward structural probes are expected to occur at low $\mathrm{SmpB}$ concentrations. This is the case, since the lower concentrations of SmpB that protect nucleotides A73-A75 (between PK1 and the tag) of tmRNA $\triangle T L D$ from being cleaved by nuclease $S 1$ are between 1 and $5 \mathrm{nM}$ (Fig. 4C), to be compared with the $20 \mathrm{nM}$ and higher SmpB concentration required to observe the reactivity changes of nucleotides from the TLD. A75 is protected at a $1 \mathrm{nM}$ concentration of SmpB and higher, whereas both A73 and A74 are protected at a $5 \mathrm{nM}$ concentration and higher. These data show that nucleotides 70-77 are involved in the high-affinity binding site. When PK4 is removed from the tmRNA, one binding site is lost (Table 2, cf. SPR data between ORF-PK2/3/4 and ORF-PK2/3). For PK4 from tmRNA $\triangle T L D$, the lower concentration of $S m p B$ that protects nucleotides A274-G277 from being cleaved by 
nuclease $\mathrm{S} 1$ is $20 \mathrm{nM}$, as for the nucleotides from the TLD. Therefore, stabilization of PK4 structure by SmpB appears only at protein concentrations around $20 \mathrm{nM}$, suggesting that PK4 contains the low-affinity site.

The lower concentrations of SmpB at which the changes in reactivity of nucleotides toward the structural probes become visible for both the TLD and for tmRNA $\triangle$ TLD are in agreement with the affinity constants measured by SPR (Fig. 2). The concentration titration with $S m p B$, with the changes in reactivity of nucleotides upstream of the tag reading frame, is also in agreement with the high-affinity binding site $\left(K_{\mathrm{D} 2}\right)$ measured by SPR (Fig. 2). Overall, these structural data reinforce both the filter binding and the SPR data and indicate, by a third experimental approach, that the highest affinity binding site of tmRNA for SmpB is outside the TLD.

\section{DISCUSSION}

The existence of a specific binding site of SmpB onto the TLD of tmRNA is well documented (e.g., Gutmann et al. 2003) and considered widely as the functional binding site during trans-translation in bacteria (for review, see Moore and Sauer 2007). Here we report by three independent and converging experimental approaches (SPR, structural probes and filter binding assays) that, in the A. aeolicus tmRNA structure, the binding site for SmpB that possesses the highest affinity is outside the TLD. There are three binding sites for SmpB on the tmRNA scaffold in solution, outside the ribosome: one on the TLD and two others outside the TLD. This result is in agreement with an earlier structural work performed on $A$. aeolicus tmRNA showing that three $\mathrm{SmpB}$ proteins can bind tmRNA in solution (Metzinger et al. 2005). Among these two additional sites, one has high ( $K_{\mathrm{D} 2}$ of $\left.1.6 \pm 0.5 \mathrm{nM}\right)$ affinity, whereas the other has lower affinity $\left(K_{\mathrm{D} 3}\right)$, comparable to that for the site on the TLD (both the $K_{\mathrm{D}}$ TLD and the $K_{\mathrm{D} 3}$ are $37 \pm 7 \mathrm{nM})$. Some of the reactivity changes toward structural probes located upstream the tag reading frame are detectable at low (1-5 nM) SmpB concentration, whereas the ones on the TLD or PK4 appear at higher (10-20 nM) protein concentration, implying the existence of a higher and a lower affinity binding site(s) outside the TLD. The detection of the structural changes induced by the protein onto the RNA, however, is limited by the specificity of each structural probe. Therefore, this report gives only some indications on the structural domains of tmRNA, outside the TLD, involved directly or indirectly in complex formation with SmpB. These results have been collected outside of the ribosomal context. We cannot formally exclude that during transtranslation, the reported $K_{\mathrm{Ds}}$ are altered and/or that other potential sites may appear.

Using various shortened tmRNA constructs derived from the A. aeolicus sequence, the two binding sites outside the TLD were delineated further: they both require the presence of nucleotides upstream the ORF, the ORF and the three downstream pseudoknots, suggesting that the conformation of an extended region of tmRNA, excluding the TLD, is required to form these two additional binding sites. Domains H5, H2, and PK1, however, are dispensable for the binding sites of SmpB outside the TLD.

Based on an incremental titration of the concentrations of SmpB inducing these reactivity changes toward structural probes, those observed upstream of the tag reading frame correspond to the higher affinity site, $K_{\mathrm{D} 2}$. These results for the interactions between SmpB and tmRNA in $A$. aeolicus agree with a recent study performed in E. coli (Konno et al. 2007). The authors show, by site-directed mutagenesis on tmRNA combined to structural probes, that nucleotides upstream of the tag reading frame interact directly with $\mathrm{SmpB}$ (in the tmRNA sequence from E. coli, U85 is the equivalent of C77 in A aeolicus). These nucleotides, if mutated in E. coli, have impaired resumption of tag translation, as previously shown elegantly by randomization selection in the resume region in vivo (Williams et al. 1999). The conformation of this RNA segment linking PK1 to the internal tag is essential for codon resumption. The presence of a high-affinity binding site for $\mathrm{SmpB}$ including this area of tmRNA, as well as chemical probing results supporting a direct interaction between the protein and the RNA at that location, suggest that SmpB sets the internal reading frame of tmRNA for ribosome decoding. In the presence of $S m p B$, the nucleotides that we find in $A$. aeolicus tmRNA to be protected against nuclease $\mathrm{S} 1$ in tmRNA $\triangle T L D$, and also in full-length tmRNA, are adjacent to those identified in E. coli by these previous studies. This interaction corresponds to the binding site that has the higher affinity for the protein, $K_{\mathrm{D} 2}$, because SmpB induces protections at low $(1-5 \mathrm{nM})$ concentrations. When this nucleotide segment and the beginning of the ORF are deleted from tmRNA, both the high- and the low-affinity binding sites are lost (Table 2, construct truncated ORF$\mathrm{PK} 2 / 3 / 4)$. A recent cryo-EM reconstruction of preaccommodated tmRNA in complex with SmpB, EF-Tu and the 70 S ribosome (Gillet et al. 2007) shows that this RNA subdomain, ORF-PK2/3/4, that contains two binding sites for $\mathrm{SmpB}$, forms a ring in solution (Fig. 5). From that structure, a reasonable explanation for loosing these binding sites, when shortening the RNA further, is that the ring formed by the internal tag and the three downstream pseudoknots gets disrupted.

This circularized conformation is most likely required for both the high $\left(K_{\mathrm{D} 2}\right)$ and the lower $\left(K_{\mathrm{D} 3}\right)$ affinity binding sites. The high-affinity site requires the presence of PK4, which is located in the vicinity of nucleotides A73A75 within the three-dimensional structure of tmRNA (Fig. 5). Indeed, when pseudoknot PK4 is removed from tmRNA (Table 2, ORF-PK2/3), the high-affinity binding site is lost, whereas a low-affinity site remains. This site may result from the conversion of the high affinity to a lower affinity site (transformation of a $2 \mathrm{nM} K_{\mathrm{D}}$ binding site in a $32 \mathrm{nM}$ 


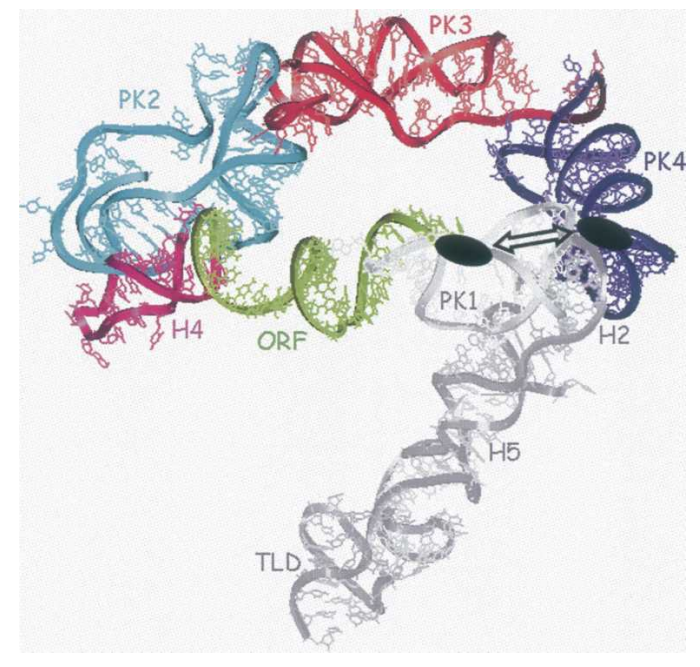

FIGURE 5. Structure of the minimal tmRNA fragment that contains the higher binding site for the SmpB protein. Reconstruction of tmRNA structure within the electron density derived from the cryoEM map for the EF-Tu-tmRNA-SmpB complex bound to the ribosome in the absence of ribosomal protein S1 (Gillet et al. 2007). The structural domains of the RNA that are dispensable for the interaction with the protein onto its high-affinity site are colored in gray ( $\mathrm{PK} 1, \mathrm{H} 2$, $\mathrm{H} 5$, and TLD). The domains that cannot be removed without loosing the binding site are color coded (the ORF is green, $\mathrm{H} 4$ is pink, PK2 is blue, PK3 is red, and PK4 is purple). Notice the spatial proximity, emphasized by the double arrow, between the reactivity changes observed upstream of the ORF and in PK4, both marked as black ovals.

$K_{\mathrm{D}}$ binding site). An initial report had suggested that PK4 could be substituted with linear sequences without loosing in vitro tmRNA activity on poly-U messengers (Nameki et al. 2000). However, a more recent report using physiological truncated mRNAs shows that replacement of PK4 by a linear sequence results in a 20 -fold decrease of transtranslation in vivo (Wower et al. 2004). Additionally, Wower et al. (2004) show that, in vitro, in presence of an excess of $S m p B$, the trans-translation of the deleted tmRNA decreases only fivefold. A reasonable hypothesis would that the deletion of PK4 results in the conversion of the high affinity to a lower affinity site $(32 \mathrm{nM})$ which, in the presence of an excess of $\mathrm{SmpB}$, could still enable tagging. Thus, our structural and SPR data, showing that PK4 contributes to the binding of SmpB outside the TLD, rationalize the results obtained by Wower et al. (2004).

Nucleotides upstream of the tag reading frame and from PK4 are both required for forming a high-affinity binding site (Table 2, cf. ORF-PK2/3, ORF-PK2/3/4, and truncated ORF-PK2/3/4). Based on the tmRNA structure derived from cryo-EM maps (Gillet et al. 2007), the distance of $\sim 51 \AA$ between nucleotides upstream of the ORF and PK4 is compatible with the binding of one SmpB protein (Dong et al. 2002). A SmpB protein could interact simultaneously with these two tmRNA binding sites through its two characterized RNA binding domains. The concentrations of $\mathrm{SmpB}$ required to induce reactivity changes at PK4, however, are four- to 20-fold higher than for nucleotides A73A75, which argues for the existence of two independent binding sites. The spatial closeness of these two SmpB binding sites onto the tmRNA scaffold suggests that during the trans-translation process, a $S \mathrm{mpB}$ protein could bind first upstream of the ORF to help determine the resuming point of translation of the internal tag reading frame, and then moves to PK4.

The results reported here show that two binding sites for SmpB are outside the TLD. The minimal RNA that sustains both sites contains nucleotides between PK1 and the tag, the tag itself, and three downstream pseudoknots. At which step does this novel high-affinity binding site for SmpB recruit the protein onto the tmRNA structure? In vivo, if tmRNA binds SmpB by its high-affinity binding site, tmRNA will be recruited to the stalled ribosomes by its sequence upstream the internal ORF. This is not the case, since during preaccommodation, tmRNA binds the stalled ribosome via an interaction involving its TLD (Kaur et al. 2006). It suggests that, in solution, SmpB does not bind tmRNA at this high-affinity site. One hypothesis is that $\mathrm{SmpB}$ has higher affinity for the ribosome than for the high-affinity site on tmRNA. A second hypothesis might be that the highaffinity site onto tmRNA is occupied by another factor. A reasonable candidate is $\mathrm{EF}-\mathrm{Tu}$, which is the most highly expressed protein in the bacterial cell. EF-Tu, in its GDP form, binds tmRNA away from the TLD, at sites near the high-affinity SmpB binding site (Zvereva et al. 2001). Alternatively, ribosomal protein S1 could also protect the high-affinity binding site on tmRNA from being accessible to $\mathrm{SmpB}$ at early stages of trans-translation, although one should take in consideration the dispensability of S1 for transpeptidation (Saguy et al. 2005). Biochemical studies revealed that the $S 1$ binding sites along tmRNA include PK2, PK3, and the tag reading frame (Wower et al. 2000; Bordeau and Felden 2002), corresponding to the shorter tmRNA fragment that retains the high-affinity site.

During preaccommodation, $\mathrm{SmpB}$ could not bind to the high-affinity site onto tmRNA, possibly because that site is hidden by structural elements from the stalled ribosome. Indeed, cryo-EM maps of tmRNA in the "preaccommodated state" show that these tmRNA domains, forming a ring, interact tightly with the head/beak of the 30 S subunit (Gillet et al. 2007). What might be the function, in the course of trans-translation, of this high-affinity binding site of SmpB on tmRNA? Nucleotides upstream the internal ORF are essential to maintain this site. If mutated, resumption of translation onto tmRNA ORF is impaired (Williams et al. 1999; Konno et al. 2007). Therefore, this is a key region of tmRNA, controlling translation of the ORF. Our results suggest that $\mathrm{SmpB}$, in addition to its role at the early stages of trans-translation, is an important player in the translation of tmRNA ORF. 


\section{MATERIAL AND METHODS}

\section{Ribonucleotides, oligodesoxynucleotides, and proteins}

All the synthetic DNA oligonucleotides were synthesized by Eurogentec. T4 polynucleotide kinase was from New England Biolabs. Taq DNA polymerase and T4 RNA ligase were from Promega. RNases $S_{1}$, $\mathrm{V}_{1}, \mathrm{U}_{2}$, and $\mathrm{T}_{1}$ were from Amersham-Pharmacia-Biotech. $\left[\alpha-{ }^{32} \mathrm{P}\right]$ ATP and $\left[\alpha-{ }^{32} \mathrm{P}\right] \mathrm{pCp}(3000 \mathrm{mCi} / \mathrm{mmol})$ were purchased from Perkin-Elmer. C-terminal his-tagged SmpB protein was overexpressed and purified as previously described (Metzinger et al. 2005).

\section{RNAs}

Purified tRNA ${ }^{\text {Phe }}$ from yeast is from Sigma. To produce the various synthetic tmRNA variants, PCR templates were amplified from a plasmid containing the entire tmRNA sequence from $A$. aeolicus (Metzinger et al. 2005). PCR primers were designed to add an upstream T7 RNA polymerase promoter, as described (Table 1). PCR products were subsequently purified using G25 columns (Promega). Alternatively, some transcripts were obtained using the antisense strand as a template, coupled with the DNA oligonucleotide sequence "TAATACGACTCACTATAG," providing a double-stranded $\mathrm{T} 7$ promoter (Table 1). In vitro transcription was performed using the Megascript kit (Ambion). To separate the transcribed RNAs from nonincorporated nucleotides, RNAs were purified using G25 columns and analyzed by PAGE to confirm sample purity. When needed, some were purified by PAGE. Native TLD was provided by S. Nonin-Lecomte (University of Paris Descartes) and its nonmodified counterpart was produced by in vitro transcription. Their sequence is described in Gaudin et al. (2003).

\section{RNA labeling}

Labeling at the $5^{\prime}$ end of the RNAs was performed with $\left[\alpha-{ }^{32} \mathrm{P}\right]$ ATP and phage T4 polynucleotide kinase after dephosphorylation with alkaline phosphatase (Silberklang et al. 1977). Labeling at the $3^{\prime}$ end was carried out by ligation of $\left[\alpha-{ }^{32} \mathrm{P}\right] \mathrm{pCp}$ using T4 RNA ligase. After labeling, the RNAs were gel purified, eluted and ethanol precipitated.

\section{"SmpB-RNA" filters binding assays}

$5^{\prime}$-Labeled RNAs were denatured for $2 \mathrm{~min}$ at $82^{\circ} \mathrm{C}$ and slowly cooled down to room temperature for $30 \mathrm{~min}$. Standard binding assays contain $0.5-1 \mathrm{pmol}$ of labeled RNAs with varying amounts of purified SmpB (up to a $1 \mu \mathrm{M}$ concentration) in a binding buffer (10 $\mathrm{mM} \mathrm{Mg}$ acetate, $3 \mathrm{mM} \beta$-mercaptoethanol, $10 \mathrm{mM} \mathrm{NH}_{4} \mathrm{Cl}$, $150 \mathrm{mM} \mathrm{KCl}, 0.05 \%$ P20, $10 \mathrm{mM}$ HEPES-KOH at $\mathrm{pH} 7.4$ ), to a final volume of $20 \mu \mathrm{L}$. After an incubation of $20 \mathrm{~min}$ at room temperature, the reaction was filtered through $0.45 \mu \mathrm{M}$ nitrocellulose disks prewet with binding buffer. Filters were washed three times with $1 \mathrm{~mL}$ of binding buffer and then with $1 \mathrm{~mL}$ of pure ethanol. The filters were air dried and the fraction of RNA retained was measured by scintillation counting.

\section{Structural probing in solution}

Labeled RNAs were heated to $82^{\circ} \mathrm{C}$ for $2 \mathrm{~min}$ in $250 \mathrm{mM}$ HEPES at pH 6.9, $250 \mathrm{mM} \mathrm{NaCl}, 25 \mathrm{mM} \mathrm{KCl}, 5 \mathrm{mM} \mathrm{MgCl}_{2}$ and slowly cooled down to room temperature. Then, labeled RNAs were incubated with or without increasing amounts of purified protein SmpB for $15 \mathrm{~min}$ at room temperature in a final volume of $20 \mu \mathrm{L}$, in presence of $1 \mu \mathrm{g}$ of total tRNA from yeast. Digestions with the various ribonucleases $\left(\mathrm{V}_{1}\right.$ at $10^{-4}$ units in $100 \mathrm{mM}$ HEPES at $\mathrm{pH} 7.5,40 \mathrm{mM}$ magnesium acetate; $S_{1}$ at 5 units in $100 \mathrm{mM}$ HEPES at $\mathrm{pH} 7.5$, $40 \mathrm{mM}$ magnesium acetate, $2 \mathrm{mM}$ zinc chloride; $\mathrm{U}_{2}$ at $2.5 \times 10^{-3}$ units in $7 \mathrm{M}$ urea at $\mathrm{pH} 4.5,25 \mathrm{mM}$ Sodium acetate, $1 \mathrm{mM}$ EDTA; and $\mathrm{T}_{1}$ at 1.25 units in $7 \mathrm{M}$ urea at $\mathrm{pH} 3.5,25 \mathrm{mM}$ Sodium acetate) and probing with lead acetate (at a final $5 \mathrm{mM}$ concentration in $125 \mathrm{mM}$ HEPES at $\mathrm{pH} 7.5,35 \mathrm{mM}$ magnesium acetate, $175 \mathrm{mM}$ potassium acetate) were performed for $15 \mathrm{~min}$ at room temperature, except for the RNases $\mathrm{U}_{2}$ and $\mathrm{T}_{1}$ ladders (incubations at $50^{\circ} \mathrm{C}$ in denaturing conditions, for the $\mathrm{A}$ and $\mathrm{G}$ sequencing ladders). Identical amounts of radioactivity were loaded per lanes. Cleavage or modification sites are detected by gel electrophoresis by direct identification with the T1 and U2 cleavage patterns of the RNA itself. We used a combination of $8 \%, 12 \%$, and $15 \%$ PAGE to analyze the tmRNA variants. The denaturing PAGE were fixed, dried, and the data were analyzed on a PhosphorImager (Molecular Dynamics). The quantitation of each fragment was scored manually.

\section{Surface plasmon resonance (SPR)}

The dissociation constants between $\mathrm{SmpB}$ and tmRNA variants were determined by SPR using BIAcore $\mathrm{X}$ biosensor system (BIAcore). For real-time analysis of molecular interactions between SmpB-His protein and tmRNA variants, $\mathrm{SmpB}$ was immobilized on a CM3 sensor chip (BIAcore) by covalent linkage between carboxymethylated dextran on the chip matrix and lysine residues in the SmpB protein as described by the supplier (BIAapplications Handbook, Biacore). Chips were equilibrated in the continuousflow buffer (10 mM HEPES at $\mathrm{pH} 7.4,150 \mathrm{mM} \mathrm{KCl}, 10 \mathrm{mM}$ $\mathrm{NH} 4 \mathrm{Cl}, 10 \mathrm{mM}$ MgOAc, $3 \mathrm{mM} \quad \beta$-mercaptoethanol, $0.05 \%$ surfactant P20). tmRNA variants were denatured by incubation at $82^{\circ} \mathrm{C}$ for $3 \mathrm{~min}$ in the flow buffer, refolded at room temperature in the continuous-flow buffer for $20 \mathrm{~min}$, and injected at various concentrations in the running buffer on 500-600 resonance units (RU) of SmpB proteins until equilibrium was reached. For the experiments performed with nonspecific RNA competitors, we have used $10 \mu \mathrm{g} / \mu \mathrm{L}$ of torula yeast total RNAs (Sigma) in the injected sample. The Sensor Chip was regenerated between each injection by a 120 -sec pulse of $50 \mathrm{mM} \mathrm{NaOH}$ containing $500 \mathrm{mM}$ $\mathrm{NaCl}$. Final curves were obtained by subtraction of the signal corresponding to the empty flow cell. For each concentration of tmRNA variants, the steady-state binding $\left(R_{\mathrm{eq}}\right)$ were measured and used to calculate the equilibrium constants of dissociation following the equation $R_{\mathrm{eq}} / C=K_{\mathrm{A}} \times R_{\max }-K_{\mathrm{A}} \times R_{\mathrm{eq}}$, where $C$ is the RNA concentration, $R_{\max }$ is the total surface binding capacity in $\mathrm{RU}$, and $R_{\mathrm{eq}}$ is the steady-state binding level in RU obtained when equilibrium was reached for each concentrations of tmRNA variants. A plot of $R_{\mathrm{eq}} / C$ against $R_{\mathrm{eq}}$ at different concentrations gives a Scatchard plot from which $K_{\mathrm{D}}\left(1 / K_{\mathrm{A}}\right)$ can be calculated.

\section{ACKNOWLEDGMENTS}

This work was supported by the ACI BCMS 136 and ANR programme MIME. We are grateful to Dr. C. Gamble and Dr. R. Gillet for proofreading and comments and to Dr. S. Nonin-Lecomte (UMR 8015, Paris, France) for the gift of a purified native TLD. This 
work was supported by grants from Région Bretagne Biomedic accueil/émergence and Esprifel.

Received April 11, 2008; accepted May 17, 2008.

\section{REFERENCES}

Barends, S., Karzai, A.W., Sauer, R.T., Wower, J., and Kraal, B. 2001. Simultaneous and functional binding of SmpB and EF-Tu-TP to the alanyl acceptor arm of tmRNA. J. Mol. Biol. 314: 9-21.

Barends, S., Bjork, K., Gultyaev, A.P., de Smit, M.H., Pleij, C.W., and Kraal, B. 2002. Functional evidence for D- and T-loop interactions in tmRNA. FEBS Lett. 514: 78-83.

Bessho, Y., Shibata, R., Sekine, S., Murayama, K., Higashijima, K., Hori-Takemoto, C., Shirouzu, M., Kuramitsu, S., and Yokoyama, S. 2007. Structural basis for functional mimicry of long-variable-arm tRNA by transfer-messenger RNA. Proc. Natl. Acad. Sci. 104: 8293-8298.

Bordeau, V. and Felden, B. 2002. Ribosomal protein S1 induces a conformational change of tmRNA; More than one protein S1 per molecule of tmRNA. Biochimie 84: 723-729.

Choy, J.S., Aung, L.L., and Karzai, A.W. 2007. Lon protease degrades tmRNA-tagged proteins. J. Bacteriol. 6: 6.

Collier, J., Binet, E., and Bouloc, P. 2002. Competition between SsrA tagging and translational termination at weak stop codons in Escherichia coli. Mol. Microbiol. 45: 745-754.

Dong, G., Nowakowski, J., and Hoffman, D.W. 2002. Structure of small protein B: The protein component of the tmRNA-SmpB system for ribosome rescue. EMBO J. 21: 1845-1854.

Felden, B., Hanawa, K., Atkins, J.F., Himeno, H., Muto, A., Gesteland, R.F., McCloskey, J.A., and Crain, P.F. 1998. Presence and location of modified nucleotides in Escherichia coli tmRNA: Structural mimicry with tRNA acceptor branches. EMBO J. 17: 3188-3196.

Gaudin, C., Nonin-Lecomte, S., Tisne, C., Corvaisier, S., Bordeau, V., Dardel, F., and Felden, B. 2003. The tRNA-like domains of E coli and A.aeolicus transfer-messenger RNA: Structural and functional studies. J. Mol. Biol. 331: 457-471.

Gillet, R., Kaur, S., Li, W., Hallier, M., Felden, B., and Frank, J. 2007. Scaffolding as an organizing principle in trans-translation. The roles of small protein B and ribosomal protein S1. J. Biol. Chem. 282: 6356-6363.

Gutmann, S., Haebel, P.W., Metzinger, L., Sutter, M., Felden, B., and Ban, N. 2003. Crystal structure of the transfer-RNA domain of transfer-messenger RNA in complex with SmpB. Nature 424: 699-703.

Hallier, M., Desreac, J., and Felden, B. 2006. Small protein B interacts with the large and the small subunits of a stalled ribosome during trans-translation. Nucleic Acids Res. 34: 1935-1943.

Hanawa-Suetsugu, K., Takagi, M., Inokuchi, H., Himeno, H., and Muto, A. 2002. SmpB functions in various steps of trans-translation. Nucleic Acids Res. 30: 1620-1629.

Jacob, Y., Sharkady, S.M., Bhardwaj, K., Sanda, A., and Williams, K.P. 2005. Function of the $\mathrm{SmpB}$ tail in transfer-messenger RNA translation revealed by a nucleus-encoded form. J. Biol. Chem. 280: 5503-5509.

Karzai, A.W., Susskind, M.M., and Sauer, R.T. 1999. SmpB, a unique RNA-binding protein essential for the peptide-tagging activity of SsrA (tmRNA). EMBO J. 18: 3793-3799.

Kaur, S., Gillet, R., Li, W., Gursky, R., and Frank, J. 2006. CryoEM visualization of transfer messenger RNA with two SmpBs in a stalled ribosome. Proc. Natl. Acad. Sci. 103: 16484-16489.
Konno, T., Kurita, D., Takada, K., Muto, A., and Himeno, H. 2007. A functional interaction of $\mathrm{SmpB}$ with tmRNA for determination of the resuming point of trans-translation. RNA 13: 1723-1731.

Metzinger, L., Hallier, M., and Felden, B. 2005. Independent binding sites of small protein B onto transfer-messenger RNA during trans-translation. Nucleic Acids Res. 33: 2384-2394.

Moore, S.D. and Sauer, R.T. 2007. The tmRNA system for translational surveillance and ribosome rescue. Annu. Rev. Biochem. 76: 101-124.

Nameki, N., Chattopadhyay, P., Himeno, H., Muto, A., and Kawai, G. 1999a. An NMR and mutational analysis of an RNA pseudoknot of Escherichia coli tmRNA involved in trans-translation. Nucleic Acids Res. 27: 3667-3675.

Nameki, N., Felden, B., Atkins, J.F., Gesteland, R.F., Himeno, H., and Muto, A. 1999b. Functional and structural analysis of a pseudoknot upstream of the tag-encoded sequence in E. coli tmRNA. J. Mol. Biol. 286: 733-744.

Nameki, N., Tadaki, T., Himeno, H., and Muto, A. 2000. Three of four pseudoknots in tmRNA are interchangeable and are substitutable with single-stranded RNAs. FEBS Lett. 470: 345-349.

Nameki, N., Someya, T., Okano, S., Suemasa, R., Kimoto, M., Hanawa-Suetsugu, K., Terada, T., Shirouzu, M., Hirao, I., Takaku, H., et al. 2005. Interaction analysis between tmRNA and SmpB from Thermus thermophilus. J. Biochem. 138: 729739.

Saguy, M., Gillet, R., Metzinger, L., and Felden, B. 2005. tmRNA and associated ligands: A puzzling relationship. Biochimie 87: 897903.

Shimizu, Y. and Ueda, T. 2002. The role of SmpB protein in transtranslation. FEBS Lett. 514: 74-77.

Silberklang, M., Prochiantz, A., Haenni, A.L., and Rajbhandary, U.L. 1977. Studies on the sequence of the 3 '-terminal region of turnip-yellow-mosaic-virus RNA. Eur. J. Biochem. 72: 465478.

Someya, T., Nameki, N., Hosoi, H., Suzuki, S., Hatanaka, H., Fujii, M., Terada, T., Shirouzu, M., Inoue, Y., Shibata, T., et al. 2003. Solution structure of a tmRNA-binding protein, $\mathrm{SmpB}$, from Thermus thermophilus. FEBS Lett. 535: 94-100.

Sundermeier, T.R., Dulebohn, D.P., Cho, H.J., and Karzai, A.W. 2005. A previously uncharacterized role for small protein $B(S m p B)$ in transfer messenger RNA-mediated trans-translation. Proc. Natl. Acad. Sci. 102: 2316-2321.

Valle, M., Gillet, R., Kaur, S., Henne, A., Ramakrishnan, V., and Frank, J. 2003. Visualizing tmRNA entry into a stalled ribosome. Science 300: 127-130.

Williams, K.P., Martindale, K.A., and Bartel, D.P. 1999. Resuming translation on tmRNA: A unique mode of determining a reading frame. EMBO J. 18: 5423-5433.

Wower, I.K., Zwieb, C.W., Guven, S.A., and Wower, J. 2000. Binding and cross-linking of tmRNA to ribosomal protein S1, on and off the Escherichia coli ribosome. EMBO J. 19: 6612-6621.

Wower, I.K., Zwieb, C., and Wower, J. 2004. Contributions of pseudoknots and protein $\mathrm{SmpB}$ to the structure and function of tmRNA in trans-translation. J. Biol. Chem. 279: 54202-54209.

Wower, J., Zwieb, C.W., Hoffman, D.W., and Wower, I.K. 2002. SmpB: A protein that binds to double-stranded segments in tmRNA and tRNA. Biochemistry 41: 8826-8836.

Zvereva, M.I., Ivanov, P.V., Teraoka, Y., Topilina, N.I., Dontsova, O.A., Bogdanov, A.A., Kalkum, M., Nierhaus, K.H., and Shpanchenko, O.V. 2001. Complex of transfer-messenger RNA and elongation factor Tu. Unexpected modes of interaction. J. Biol. Chem. 276: 47702-47708. 

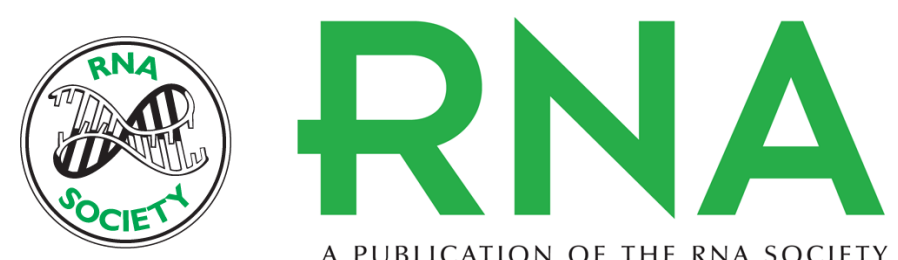

A PUBLICATION OF THE RNA SOCIETY

\section{The highest affinity binding site of small protein B on transfer messenger RNA is outside the tRNA domain}

Laurent Metzinger, Marc Hallier and Brice Felden

RNA 2008 14: 1761-1772

References This article cites 34 articles, 14 of which can be accessed free at: http://rnajournal.cshlp.org/content/14/9/1761.full.html\#ref-list-1

\section{License}

Email Alerting

Receive free email alerts when new articles cite this article - sign up in the box at the Service top right corner of the article or click here. 